\title{
Efek Olive Oil dan Virgin Coconut Oil terhadap Striae Gravidarum
}

\author{
Evi Pratami, ${ }^{1}$ Wiryawan Permadi, ${ }^{2}$ Sharon Gondodiputro ${ }^{3}$ \\ ${ }^{1}$ Program Studi Kebidanan Sutomo Jurusan Kebidanan Politeknik Kesehatan Kemenkes Surabaya, \\ ${ }^{2}$ Departemen Obstetri dan Ginekologi Fakultas Kedokteran Universitas Padjadjaran/Rumah Sakit Dr. \\ Hasan Sadikin Bandung, ${ }^{3}$ Departemen Ilmu Kesehatan Masyarakat Fakultas Kedokteran Universitas \\ Padjadjaran
}

\begin{abstract}
Abstrak
Prevalensi striae gravidarum (SG) pada ibu hamil berkisar 50\% sampai 90\%. Efek SG menyebabkan rasa gatal, panas, dan kering serta gangguan emosional sehingga menimbulkan masalah kosmetik pada sebagian besar ibu. Saat ini banyak ibu hamil menggunakan olive oil untuk mencegah SG, namun minyak ini relatif sukar didapat dan harganya mahal. Di Indonesia dikenal minyak lain yaitu virgin coconut oil (VCO) yang memiliki kandungan efektif untuk menjaga elastisitas kulit, minyak ini mudah didapat dan murah. Penelitian ini bertujuan menganalisis perbedaan dan korelasi efek olive oil dan VCO terhadap SG. Penelitian ini dilaksanakan pada bulan Maret-Juli 2012. Rancangan penelitian ini merupakan penelitian klinis melalui pendekatan eksperimental. Subjek penelitian adalah 80 ibu hamil di wilayah Dinas Kesehatan Kota Surabaya dan dikelompokkan menjadi 2 kelompok dengan menggunakan random permuted blocks. Hasil penelitian menunjukkan tidak terdapat perbedaan SG berdasarkan jumlah garis dan tingkat eritema antara kelompok yang menggunakan olive oil dan VCO $(\mathrm{p}=0,156$ dan 1,00$)$. Selanjutnya terdapat korelasi kuat antara kelompok olive oil dan VCO dengan jumlah garis $(\mathrm{r}=-0,576$ dan $-0,560)$ dan tingkat eritema $(\mathrm{r}=-0,699$ dan -0,586). Simpulan, tidak ada perbedaan efek olive oil dengan VCO terhadap SG. [MKB. 2014;46(1):1-5]
\end{abstract}

Kata kunci: Olive oil, striae gravidarum, virgin coconut oil

\section{Effects of Olive Oil and Virgin Coconut Oil against Striae Gravidarum}

\begin{abstract}
The prevalence of striae gravidarum (SG) in pregnant women ranges from $50 \%$ to $90 \%$. Effects of SG include itchy and hot feeling as well as dry skin. This situation also causes emotional disturbances that poses a cosmetic problem for most pregnant women. Nowadays, many pregnant women use olive oil to prevent SG, but it is relatively difficult to find and costly. In Indonesia, a similar oil, virgin coconut oil (VCO), has been used by many pregnant women for the same reason. The aim of this study was to analyze the differences and correlation between effects of olive oil and VCO against SG. The study was conducted in March-July 2012. An experimental study was performed on 80 pregnant women in Surabaya Municipality and they were divided into 2 groups using random permuted blocks. The results of this study showed that there was no difference in SG appearance based on the number of lines and levels of erythema between groups $(\mathrm{p}=0.156$ and 1.00$)$. Furthermore, there was a strong negative correlation between the effect of olive oil or VCO on the number of lines $(r=-0.576$ and -0.560$)$ and the level of erythema $(\mathrm{r}=-0.699$ and -0.586). In conclusion, there is no difference in the effect of olive oil and VCO against SG. [MKB. 2014;46(1):1-5]
\end{abstract}

Key words: Olive oil, striae gravidarum, virgin coconut oil 


\section{Pendahuluan}

Kehamilan akan memengaruhi tubuh ibu secara keseluruhandenganmenimbulkan perubahan pada seluruh sistem organ. Sebagian besar perubahan pada tubuh ibu-ibu hamil tersebut disebabkan oleh faktor hormonal (esterogen, progesteron, human chorionic gonadotropin, dan relaksin). Perubahan pada kulit yaitu tampak permukaan kulit sangat teregang yang mengakibatkan serabut kolagen mengalami ruptur yang disebut striae gravidarum (SG). Pada minggu ke-18 hingga 32 terjadi over distance dinding abdomen dan SG sangat berhubungan dengan hormon relaksin. Sekresi relaksin tersebur akan ditingkatkan oleh human chorionic gonadotropin. Sekresi hormon ini akan menurun setelah minggu ke-24 sehingga risiko munculnya SG menjadi lebih tinggi. ${ }^{1}$ Berdasarkan hal tersebut maka dalam penelitian ini usia kehamilan 18-24 minggu menjadi awal dimulainya penelitian.

Prevalensi SG pada ibu hamil 50-90\%. Efek SG menyebabkan rasa gatal, panas, kering, dan gangguan emosional karena hal ini menimbulkan masalah kosmetik terhadap sebagian besar ibu hamil. ${ }^{2,3}$ Beberapa penelitian telah membuktikan predisposisi SG antara lain hormonal, elastisitas kulit, serta peregangan mekanik. ${ }^{4}$ Saat ini, banyak ibu hamil menggunakan olive oil untuk mencegah $\mathrm{SG}$, namun minyak ini relatif sukar didapat dan harganya mahal. Di Indonesia dikenal minyak lain yaitu virgin coconut oil (VCO) atau minyak kelapa murni yang memiliki kandungan asam laurat dan asam oleat yang efektif untuk menjaga elastisitas kulit sebagai salah satu predisposisi penyebab munculnya $\mathrm{SG},{ }^{5,6}$ selain itu minyak ini mudah didapat dan murah.

Olive oil merupakan produk yang didapatkan dari ekstraksi mekanik buah Olea europeae $L$. (termasuk keluarga Oleaceae) yang mengandung $70 \%-80 \%$ asam lemak, efeknya terhadap kulit yaitu meningkatkan penyerapan zat yang dibawa (squalene, a tokoferol, dan sterol). Komponen minor lain yang ada di dalam olive oil adalah hidrokarbon, seperti squalene (komponen utama zat pelicin dan penghalus) dan $B$ karoten. Olive oil juga mengandung $\alpha$ tokoferol sebesar 10,6\% yang bermanfaat menjaga elastisitas kulit, fatty alkohol, waxes, pigmen (klorofil dan karotenoid), dan sterol yang berfungsi menjaga kelenturan kolagen..$^{7-9}$

Kandungan virgin coconut oil terdiri atas $92 \%$ asam lemak jenuh yang meliputi $48-53 \%$ asam laurat, $1,5-2,5 \%$ asam oleat dan asam lemak lainnya seperti $8 \%$ asam kaprilat, serta $7 \%$ asam kaprat. Kandungan asam lemak (terutama asam laurat dan oleat) bersifat melembutkan kulit, di samping itu, VCO mengandung vitamin A, C, dan E yang efektif digunakan sebagai moisturizer sehingga meningkatkan permeabilitas kulit, ${ }^{6,10}$ serta mampu menjaga elastisitas kulit.

Penelitian ini bertujuan untuk menganalisis perbedaan dan korelasi efek olive oil dan virgin coconut oil topikal terhadap striae gravidarum berdasarkan jumlah garis dan tingkat eritema.

\section{Metode}

Penelitian ini merupakan penelitian klinis dengan pendekatan eksperimental memakai rancangan paralel. Objek penelitian dengan menggunakan produk jadi. Populasi adalah seluruh ibu hamil di wilayah Surabaya. Sampel penelitian adalah sebagian dari populasi yang memenuhi kriteria inklusi dan tidak termasuk kriteria eksklusi. Kriteria inklusi yaitu primigravida, ibu hamil 18 sampai 24 minggu, hamil tunggal, usia ibu $\leq 35$ tahun, mempunyai keturunan SG (ibu dan atau saudara perempuan), mempunyai tipe kulit V dan VI berdasarkan klasifikasi Fitzpatrick, ${ }^{11}$ selama penelitian responden bertempat tinggal di Surabaya, bersedia menjadi subjek penelitian yang telah dibuktikan dengan menandatangani persetujuan menjadi responden. Kriteria eksklusi: mengonsumsi alkohol, menggunakan krim untuk tujuan mencegah SG, dan pada saat pengkajian awal muncul SG.

Ukuran sampel berdasarkan uji satu arah, taraf kemaknaan $5 \%$, power of the test $80 \%$, $\mathrm{p}_{1}$ : 0,67 didapatkan 36 responden per kelompok. Pengelompokan berdasarkan random permuted blocks, ${ }^{12}$ selanjutnya selama penelitian terdapat 4 responden drop out. Penelitian dilakukan pada bulan Maret-Juli 2012.

Variabel bebas penelitian ini adalah olive oil dan VCO yang diberikan secara topikal, sedangkan variabel terikat yaitu SG yang didasarkan pada jumlah garis dan tingkat eritema. Jumlah garis yang dimaksudkan adalah perhitungan garisgaris striae yang muncul pada kehamilan 34 minggu, sedangkan tingkat eritema adalah warna garis yang muncul dengan klasifikasi merah muda untuk kategori ringan, merah tua untuk kategori sedang, dan ungu untuk kategori berat, Prosedur pengolesan dilakukan oleh responden pada perut (dengan batas atas dan bawah dari xyphoid sampai simfisis pubis dan batas samping adalah linea mid aksilaris kanan dan kiri) dengan frekuensi sehari dua kali setelah mandi sebanyak $2 \mathrm{~mL}$ dimulai dari awal penelitian sampai usia kehamilan 34 minggu.

Data dianalisis dengan mempergunakan Uji Mann-Whitney untuk menilai perbedaan jumlah garis yang muncul (skala rasio) pada kelompok olive oil dan VCO (skala nominal), Fisher Exact 
Tabel 1 Perbandingan Kemunculan Garis Striae Gravidarum antara Kelompok Olive Oil dan Kelompok VCO

\begin{tabular}{lccc}
\hline & \multicolumn{2}{c}{ Kelompok } & \\
\cline { 2 - 3 } & Olive Oil & VCO & \multirow{2}{*}{ Total } \\
\cline { 2 - 3 } & $\mathbf{n}$ & $\mathbf{n}$ & \\
\hline Tidak muncul & 19 & 27 & 46 \\
garis & 20 & 14 & 34 \\
Muncul garis & 39 & 41 & 80 \\
Total & & & \\
\hline
\end{tabular}

menilai perbedaan tingkat eritema pada garis yang muncul (skala ordinal) pada kelompok olive oil dan VCO (skala nominal), Pearson untuk menilai korelasi volume pengolesan dengan jumlah garis, dan Spearman untuk menilai korelasi volume pengolesan dengan tingkat eritema. Klasifikasi kekuatan korelasi berdasarkan Colton. ${ }^{12}$

\section{Hasil}

Virgin coconut oil (VCO) lebih mampu mencegah munculnya SG daripada olive oil (Tabel 1), tanpa memperhatikan spesifikasi garis yang muncul (rata-rata pada kedua kelompok maupun tingkat eritema). Berdasarkan kaitan dengan kandungan yang ada pada kedua minyak, VCO mengandung lebih banyak zat yang mampu menjaga elastisitas kulit (tanpa memperhatikan sifat kedua minyak).

Berbeda dengan data diskriptif pada Tabel 1, setelah dilakukan uji, ternyata tidak mempunyai perbedaan rata-rata antara kedua kelompok penelitian (Tabel 2). Olive oil bersifat hidrofobik dan hidrofilik sehingga area masuknya minyak akan lebih luas yaitu melalui epidermis, kelenjar lemak dan rambut, tetapi potensi menguapnya juga menjadi tinggi virgin coconut oil hanya bersifat hidrofobik menyebabkan area masuknya minyak hanya melewati epidermis dan rambut, tetapi potensi menguap sangat kecil. Berdasarkan hasil penelitian ini ternyata tidak ada perbedaan rata-rata pada kedua kelompok subjek terhadap efek jumlah garis yang muncul.

Penilaian tingkat eritema berdasarkan garis
Tabel 3 Perbedaan Tingkat Eritema berdasarkan Kelompok Subjek

\begin{tabular}{|c|c|c|c|c|}
\hline \multirow{3}{*}{$\begin{array}{l}\text { Tingkat } \\
\text { Eritema }\end{array}$} & \multicolumn{2}{|c|}{ Kelompok } & \multirow{3}{*}{ Total } & \multirow{3}{*}{$\mathbf{p}$} \\
\hline & Olive Oil & VCO & & \\
\hline & $\mathbf{n}$ & $\mathbf{n}$ & & \\
\hline Ringan & 5 & 2 & 7 & 1,00 \\
\hline $\begin{array}{l}\text { Sedang }+ \\
\text { berat }\end{array}$ & 15 & 12 & 27 & \\
\hline Total & 20 & 14 & 34 & \\
\hline
\end{tabular}

Keterangan *) dilakukan Uji Fisher Exact

yang muncul pada kedua kelompok, sehingga diperoleh tabulasi silang tingkat eritema pada kelompok olive oil dan VCO (Tabel 3).

Tidak berbeda dengan efek minyak terhadap jumlah garis yang dinilai pada akhir penelitian, berdasarkan tingkat eritema terhadap garis yang muncul juga tidak menunjukkan perbedaan. Pada kedua kelompok terbanyak pada tingkat eritema sedang dan berat (Tabel 3). Hal ini berarti waktu awal keluar garis pada kedua kelompok terjadi dalam waktu yang hampir bersamaan, sehingga tingkat eritema yang dinilai pada akhir masa penelitian tidak berbeda.

Korelasi efek olive oil terhadap jumlah garis yang muncul berkategori kuat, artinya kandungan dan sifat yang ada dalam olive oil dapat terserap secara kuat untuk mencegah munculnya SG, demikian juga pada VCO (Tabel 4). Berdasarkan hasil pengamatan seperti yang terlihat pada tabel sebelumnya, kedua minyak memiliki kandungan serta sifat yang berbeda, namun setelah dilakukan uji per masing-masing subjek ternyata keduanya menunjukkan korelasi yang sama kuat.

Hasil uji korelasi volume pengolesan olive oil dengan tingkat eritema yang terdapat pada garis SG yang muncul didapatkan nilai korelasi dengan kategori kuat, demikian juga korelasi volume pengolesan VCO dengan tingkat eritema didapatkan nilai korelasi kuat (Tabel 5). Tabel di atas menunjukkan bahwa onset awal keluarnya striae terjadi pada waktu yang hampir bersamaan baik pada kelompok olive oil maupun VCO. Meskipun olive oil itu bersifat hidrofobik dan hidrofilik (area serapan dan penguapan luas)

Tabel 2 Jumlah Garis Rata-rata berdasarkan Kelompok Subjek

\begin{tabular}{ccccccc}
\hline \multirow{2}{*}{$\begin{array}{c}\text { Jumlah } \\
\text { Garis }\end{array}$} & Kelompok & $\mathbf{n}$ & Min & Maks & Rata-rata & p \\
\cline { 2 - 7 } & Olive oil & 39 & 0 & 50 & 11 & \multirow{2}{*}{0,156} \\
\hline & VCO & 41 & 0 & 35 & 7 & \\
\hline
\end{tabular}

Keterangan *) dilakukan uji Mann-Whitney 
Tabel 4 Korelasi Volume Pengolesan pada Kelompok Subjek terhadap Jumlah Garis

\begin{tabular}{cccc}
\hline \multirow{3}{*}{ Jumlah garis } & $*$ ) & Olive Oil & VCO \\
\cline { 2 - 4 } & $\mathrm{r}$ & $-0,576$ & $-0,560$ \\
& $\mathrm{p}$ & $<0,001$ & $<0,001$ \\
& $\mathrm{n}$ & 39 & 41 \\
\hline
\end{tabular}

Keterangan *) dilakukan Uji Pearson

dan VCO hanya hidrofobik (area serapan dan penguapan lebih sempit), namun pada akhirnya kedua minyak memiliki efek yang sama terdapat waktu keluarnya garis.

\section{Pembahasan}

Penelitian telah dilaksanakan dan mendapatkan hasil bahwa tidak terdapat perbedaan efek yang ditimbulkan oleh olive oil maupun VCO yang diberikan secara topikal berdasarkan jumlah garis maupun tingkat eritema. Demikian pula korelasi yang didapatkan, pada kedua kelompok terhadap SG berdasarkan jumlah garis dan tingkat eritema berada pada tingkat korelasi yang kuat.

Dermis memberikan kekuatan elastisitas dan kelembutan kulit. Dermis terdiri atas 2 lapisan yaitu lapisan atas (stratum papilare) dan lapisan bawah (stratum retikularis). Kedua lapisan ini terdiri atas jaringan ikat longgar yang tersusun dari serabut yaitu serabut kolagen, elastik, dan serabut retikulus. Serabut elastis tersebut saling beranyaman dan masing-masing memiliki fungsi berbeda. Serabut kolagen memberikan kekuatan pada kulit, serabut elastik memberikan kelenturan kulit, dan retikulus terutama di sekitar kelenjar serta folikel rambut memberikan kekuatan pada lapisan tersebut. ${ }^{13}$ Minyak yang diberikan secara dioleskan akan mampu menembus hingga lapisan dermis kulit.

Kemajuan SG melalui tiga tahapan: tahap akut ditandai dengan timbul warna merah muda dan sedikit menonjol, tahap subakut dengan warna yang lebih pekat, tahap kronik ditandai dengan hipopigmentasi dan atropi striae (alba). Warna striae cenderung meningkat yang seiring dengan pertambahan waktu hingga diperoleh warna yang lebih gelap, akhirnya berkembang menjadi striae alba yang tampak putih, rata, dan cekung setelah 6-10 bulan. ${ }^{14-16}$

Gradasi warna yang ditimbulkan oleh SG akan dapat memprediksi waktu onset awal munculnya SG, misalnya warna merah yang lebih tua menandakan muncul lebih awal dibandingkan dengan yang warna merah muda. Hasil penelitian
Tabel 5 Korelasi Volume Pengolesan pada Kelompok Subjek terhadap Tingkat Eritema

\begin{tabular}{cccc}
\hline \multirow{4}{*}{ Jumlah garis } & $*$ ) & Olive Oil & VCO \\
\cline { 2 - 4 } & $\mathrm{r}$ & $-0,699$ & $-0,586$ \\
& $\mathrm{p}$ & $<0,001$ & $<0,001$ \\
& $\mathrm{n}$ & 20 & 14 \\
\hline
\end{tabular}

Keterangan *) dilakukan Uji Spearman

ini mendapatkan bahwa antara kelompok yang pengolesannya menggunakan olive oil maupun VCO setelah diamati pada kehamilan 34 minggu, berada pada tingkat eritema sedang berat yaitu warna merah tua hingga ungu, sehingga setelah diuji secara statistik tidak menunjukkan perbedaan bermakna antara kedua kelompok.

Kandungan dalam olive oil yaitu asam oleat fenolat, sterol, squalene, a tokoferol dan flavonoid, sama fungsinya dengan kandungan yang ada dalam VCO yaitu asam laurat, asam oleat, $\alpha$ tokoferol, vitamin A, omega 3, dan moisturizer. Kandungan di dalam VCO yang tidak terdapat dalam olive oil adalah vitamin $\mathrm{C}$ dan kadar air yang rendah. Olive oil bersifat hidrofobik dan hidrofilik sehingga area masuknya minyak lebih luas yaitu melalui selaput epidermis, kelenjar lemak, serta rambut tetapi potensi menguapnya menjadi tinggi, sedangkan VCO hanya bersifat hidrofobik sehingga tempat masuknya minyak hanya melewati epidermis dan juga rambut, tetapi potensi menguap sangat kecil..$^{6-9}$

Sintesis dan kekuatan kolagen dipengaruhi oleh vitamin $\mathrm{C}$, kerapuhan kolagen menunjukkan derajateritema pada striae gravidarum. Perubahan derajat eritema pada SG merupakan akibat dari atropi dan pendataran pada struktur epidermis, sedangkan vitamin A berfungsi menjaga struktur epidermis. Virgin coconut oil merupakan minyak yang kaya akan vitamin $C$, tetapi tidak terdapat dalam minyak olive oil. ${ }^{6,10,16-18}$

Peneliti belum menemukan penelitian serupa yang menganalisis perbedaan efek olive oil dengan VCO terhadap SG berdasarkan tingkat eritema. Penelitian yang sudah dilaksanakan menganalisis masing-masing minyak secara terpisah terhadap SG hanya berdasarkan garis.

Penelitian di Iran ${ }^{19}$ tahun 2011 dengan tujuan menentukan efek olive oil pada SG yang terjadi dalam trimester kedua kehamilan. Striae terjadi pada $40 \%$ wanita yang menggunakan olive oil, sementara striae terjadi $50 \%$ kelompok kontrol. Penelitian ini menyimpulkan penggunaan olive oil sampai akhir trimester kedua kehamilan tidak efektif untuk mengurangi SG.

Penelitian di Filipina ${ }^{20}$ tahun 2008 bertujuan 
menilai efektivitas VCO untuk mencegah SG, dan mendapatkan hasil kejadian SG pada kelompok VCO tidak berbeda dengan kelompok kontrol, namun luas striae lebih kecil dan onset terjadinya SG lebih lambat daripada kelompok kontrol (28 minggu pada kelompok kontrol dan 32 minggu pada kelompok perlakuan).

Penelitian yang telah dilakukan di Bangkok ${ }^{4}$ didapatkan hasil bahwa munculnya SG rata-rata berkisar pada usia kehamilan 23,4 $\pm 5,3$ minggu, hanya $7,3 \%$ yang muncul pada kehamilan sebelum 12 minggu dan $6,5 \%$ setelah kehamilan 28 minggu, sementara $26,1 \%$ dan $60,1 \%$ berkembang pada usia kehamilan masing-masing 12 sampai 20 minggu dan 20-28 minggu. Hasil penelitian ini tidak menganalisis mulai munculnya SG, tetapi menginformasikan bahwa pada saat kehamilan 34 minggu tidak ada perbedaan yang signifikan antara olive oil maupun VCO terhadap eritema yang muncul. Keterangan ini menandakan bahwa SG muncul dalam waktu yang tidak berbeda pada kedua kelompok.

Simpulan, timbulnya SG berdasarkan jumlah garis dan tingkat eritema pada kelompok yang pengolesannya mempergunakan olive oil tidak berbeda dengan VCO. Terdapat korelasi negatif yang sama kuat antara pengolesan olive oil dan VCO terhadap SG berdasarkan jumlah garis dan tingkat eritema. Saran pada penelitian ini adalah melakukan penelitian lanjutan dengan melakukan observasi ketat pengolesan minyak mulai dari awal hingga akhir penelitian.

\section{Daftar Pustaka}

1. Cunningham FG, Gant NF, Leveno KJ, Gilstrap LC, Hauth JC, Wenstrom KD, dkk. Williams obstetrics. Edisi ke-23. New York: Mc Graw Medical; 2010.

2. Osman H, Rubeiz N, Tamim H, Nassar AH. Risk factors for the development of striae gravidarum. Am J Obstet Gynecol. 2007;196(1):62.e1-5.

3. Salter SA, Kimball AB. Striae gravidarum. Clin Dermatol. 2006;24(2):97-100.

4. Lerdpienpitayakul $\mathrm{R}$, Manusirivithaya S, Wiriyasirivaj B, Lorwatthanasirikul J. Prevalence and risk factors of striae gravidarum in primiparae. Thai $\mathrm{J}$ Obstet Gynecol. 2009;17:70-9.

5. Henny L, Salman, Sukma HM. Uji daya peningkat penetrasi virgin coconut oil (VCO) dalam basis krim. Jurnal Sains dan Teknologi Farmasi. 2008;13(1):13-6.

6. Fu PP, Howard PC, Culp SJ, Xia Q, Webb PJ, Blankeship LR, dkk. Do topically applied skin creams containing retinyl palmitate affect the photocarcinogenecity of simulated solar light? J Food Drug Analysis. 2002;10 (4):262-8.

7. Covas MI, Gutie'rrez VR, Torre, Kafatos A, Ravento's RM, Osada J, dkk. Minor components of olive oil: evidence to date of health benefits in humans. Nutr Rev. 2006; 64(10):S20-30.

8. Mailer R. Chemistry and quality of olive oil. NSW Departmen of Primary Industries [Online Serial] 2006 [diunduh 17 November 2011]. Tersedia dari: http//www.dpi.nsw.gov. au/primefacts.

9. Tripoli E, Giammanco M, Tabacchi G, Majo D, Giammanco S, La Guardia M. The phenolic compounds of olive oil: structure, biological activity and beneficial effects on human health. Nutr Res Rev. 2005;18(1):98-112.

10. Krishna, Gopala AG, Gaurav R, Singh BA, Prasanth K, Preeti C. Coconut oil: chemistry, production and its applications-a review. Indian Coconut J. 2010;73(3):15-27.

11. Silonie S. Fitzpatrick skin typing: applications in dermatology. IJDVL. 2008;75:93-6.

12. Sudigdo S, Sofyan I. Dasar-dasar metodologi penelitian klinis. Jakarta: Sagung Seto; 2010.

13. Paul A, Tie TE. Kapita selekta dermatovenerologi. Jakarta: EGC; 2003.

14. Goldman A, Rossato F, Prati C. Stretch marks: treatment using the 1,064-nm Nd:YAG laser. Dermatol Surg. 2008;34(5):686-91.

15. Bleve M, Capra P, Pavanetto F, Perugini P. Ultrasound and 3D skin imaging: methods to evaluate efficacy of striae distensae treatment. Dermatol Res Prac. 2012;2012:673-706.

16. Piérard-Franchimont C, Hermanns JF, Hermanns-LêT, Piérard GE. Striae distensae in darker skin types: the influence of melanocyte mechanobiology. Cosmet Dermatol. 2005;4(3):174-8.

17. Nielsen JB. Natural oils affect the human skin integrity and the percutaneous penetration of benzoic acid dose-dependently. Basic Clin Pharmacol Toxicol. 2006;98(6):575-81.

18. Mohammad A. Formulasi obat topikal dengan dasar penyakit kulit. Yogyakarta: Gadjah Mada University Press; 2002.

19. Taavoni S, Soltanipour F, Haghani H, Ansarian H, Kheirkhah M. Effect of olive oil on striae gravidarum in the second trimester of pregnancy. Complement Ther Clin Pract. 2011;17(3):167-9.

20. Trifina. Efektifitas minyak kelapa murni (virgin coconut oil) topikal untuk mencegah striae gravidarum [tesis]. Bandung: Universitas Padjadjaran; 2008. 